\title{
Eu acolho, tu acolhes, nós acolhemos: acolhimento grupal na Atenção Básica
}

\author{
I embrace, you embrace, we embrace: group reception in Primary Health Care \\ Yo acojo, tú acoges, nosotros acogemos: acogida grupal en Atención Primária de Salud
}

Recebido: 20/12/2021 | Revisado: 29/12/2021 | Aceito: 31/12/2021 | Publicado: 08/01/2022

\author{
Nadilu Cardoso Drumond \\ ORCID: https://orcid.org/0000-0003-4527-9781 \\ Universidade Federal do Espírito Santo, Brasil \\ E-mail: nadiludrumond@gmail.com \\ Alana Pereira Rodrigues \\ ORCID: https://orcid.org/0000-0002-9922-4121 \\ Prefeitura Municipal de Vitória, Espírito Santo, Brasil \\ E-mail: alanapr@gmail.com \\ Alexandra Iglesias \\ ORCID: https://orcid.org/0000-0001-7188-9650 \\ Universidade Federal do Espírito Santo, Brasil \\ E-mail: leiglesias@gmail.com
}

\begin{abstract}
Resumo
O objetivo deste trabalho consiste em apresentar uma experiência de acolhimento grupal em saúde mental em uma Unidade de Saúde da Família do município de Vitória-ES, em parceria com um projeto de extensão universitária. Os encontros eram conduzidos por uma psicóloga e uma graduanda em Psicologia, aconteciam uma vez por semana, com duração média de duas horas e participação de cerca de cinco usuários. Durante esses encontros, o principal recurso utilizado eram imagens extraídas de revistas, com o intuito de auxiliar os usuários a se expressarem e falarem das razões que os levaram a buscar o serviço de saúde. Essa configuração de acolhimento se mostrou bastante potente, uma vez que os participantes se sentiam confortáveis para falar de suas angústias, se acolhiam e trocavam experiências entre si. Ao compartilhar com seus pares, os participantes percebiam que suas queixas não eram só suas, mas que também se concretizavam na vida de outras pessoas que moravam no mesmo território. Neste sentido, os participantes não ocupavam um lugar passivo, mas de sujeitos autônomos e protagonistas de seu processo de saúde. Além disso, tal formato de acolhimento, contribuiu para ampliar as perspectivas a respeito da atuação da Psicologia para além do atendimento clínico tradicional. No entanto, também houve alguns desafios na realização de tal atividade, sobretudo no que diz respeito à condução do grupo e a falta de infraestrutura da Unidade de Saúde da Família.
\end{abstract}

Palavras-chave: Acolhimento; Atenção básica; Saúde mental; Psicologia; Extensão universitária.

\begin{abstract}
The objective of this work is to present an experience of group welcoming in mental health in a Family Health Unit in the city of Vitória-ES, in partnership with a university extension project. The meetings were conducted by a psychologist and a Psychology undergraduate, held once a week, with an average duration of two hours and the participation of about five users. During these meetings, the main resource used was images extracted from magazines, with the aim of helping users to express themselves and talk about the reasons that led them to seek the health service. This host configuration proved to be quite powerful, as the participants felt comfortable talking about their anxieties, welcomed each other and exchanged experiences among themselves. By sharing with their peers, participants realized that their complaints were not only their own, but that they were also materialized in the lives of other people living in the same territory. In this sense, the participants did not occupy a passive place, but as autonomous subjects and protagonists of their health process. In addition, such a reception format contributed to broadening perspectives regarding the role of Psychology beyond traditional clinical care. However, there were also some challenges in carrying out such activity, especially with regard to conducting the group and the lack of infrastructure at the Family Health Unit.
\end{abstract}

Keywords: User embracement; Primary health care; Mental health; Psychology; University extension.

\section{Resumen}

El objetivo de este trabajo es presentar una experiencia de acogida grupal en salud mental en una Unidad de Salud de la Familia en la ciudad de Vitória-ES, en alianza con un proyecto de extensión universitaria. Los encuentros estuvieron a cargo de un psicólogo y un estudiante de posgrado en Psicología, se realizaron una vez por semana, con una duración promedio de dos horas y la participación de unos cinco usuarios. Durante estos encuentros, el principal recurso utilizado fueron las imágenes extraídas de revistas, con el objetivo de ayudar a los usuarios a expresarse y hablar sobre los motivos que los llevaron a buscar el servicio de salud. Esta configuración de anfitrión resultó ser bastante poderosa, ya que los participantes se sintieron cómodos hablando de sus ansiedades, se dieron la bienvenida e intercambiaron experiencias 
entre ellos. Al compartir con sus compañeros, los participantes se dieron cuenta de que sus quejas no eran solo las suyas, sino que también se materializaban en la vida de otras personas que viven en el mismo territorio. En este sentido, los participantes no ocuparon un lugar pasivo, sino como sujetos autónomos y protagonistas de su proceso de salud. Además, este formato de recepción contribuyó a ampliar las perspectivas sobre el papel de la Psicología más allá de la atención clínica tradicional. Sin embargo, también hubo algunos desafíos en el desarrollo de dicha actividad, especialmente en lo que respecta a la conducción del grupo y la falta de infraestructura en la Unidad de Salud de la Familia.

Palabras clave: Acogimiento; Atención primaria de salud; Salud mental; Psicología; Extensión universitaria.

\section{Introdução}

A implantação e consolidação do Sistema Único de Saúde (SUS) possibilitou o direito à saúde para toda população e rompeu com a concepção de saúde atrelada unicamente à ausência de doença (Alexandre e Romagnoli, 2017). Neste sentido, a saúde passou a ser concebida de forma ampla, como resultado de um conjunto de fatores (biológico, econômico e sociais) que atravessam o modo de vida das pessoas. A efetivação dessa premissa, todavia, encontra obstáculos, visto que ainda há no SUS práticas e ações que priorizam a doença em detrimento dos sujeitos. É neste cenário que surge a Política Nacional de Humanização (PNH), que busca fortalecer as relações e valorizar os atores envolvidos na saúde (Hoffmann, 2009).

Publicada em 2003, a PNH aposta no trabalho coletivo cotidiano para concretizar práticas e ações humanizadas que, por sua vez, estimulam a corresponsabilidade dos profissionais em seu trabalho e dos usuários no autocuidado. Essa política assume a importância do diálogo entre diferentes saberes, da integração entre gestão e cuidado e do protagonismo dos sujeitos. Para tanto, a PNH se orienta por alguns conceitos, especialmente: gestão participativa e cogestão, clínica ampliada e compartilhada e acolhimento (Brasil, 2013a).

Destaca-se neste trabalho, o acolhimento, o qual consiste em um dispositivo que busca potencializar os encontros entre profissionais e usuários, de modo que a queixa de cada indivíduo possa ser acolhida e reconhecida. Para tanto, o acolhimento requer uma escuta disponível, que permite a produção de vínculo, relações de confiança, responsabilização e resolutividade dos recursos da saúde (Brasil, 2010; Brasil, 2013a). Nesta perspectiva, o acolhimento pode e deve ser realizado por qualquer profissional e em qualquer lugar, já que se configura como uma postura ética. Assim, essa ferramenta se diferencia da triagem, por exemplo, pois não se caracteriza como uma etapa, mas algo inerente a todos serviços e procedimentos (Hoffmann, 2009; Brasil, 2010).

Além disso, ter uma postura acolhedora pressupõe estar atento e aberto às diversidades (culturais, raciais ou étnicas) e a avaliação feita pelo próprio usuário, reconhecendo-o como participante ativo no processo de produção de sua saúde (Brasil, 2010; Lazzarotto e Castro, 2017). Assim:

o acolhimento (...) requer prestar um atendimento com resolutividade e responsabilização, orientando, quando for o caso, o paciente e a família em relação a outros serviços de saúde, para a continuidade da assistência, e estabelecendo articulações com esses serviços, para garantir a eficácia desses encaminhamentos (Brasil, 2010, p. 21).

Dessa forma, entende-se neste estudo, o acolhimento como um dispositivo que permite o desenvolvimento de relações afetivas e recíprocas entre os indivíduos. Nesta discussão, a Atenção Básica (AB) se apresenta no SUS como favorável a construção destas relações, tendo em vista sua proximidade com o território. Trata-se da porta de entrada preferencial do usuário no sistema de saúde, que tem como um de seus fundamentos, o desenvolvimento de vínculo entre a equipe e a população, para a continuidade e longitudinalidade do cuidado (Brasil, 2006). 
Nesta organização da AB, a Estratégia de Saúde da Família (ESF) se destaca, dentre outros motivos, por sua proposta de consolidação da integralidade do cuidado, por meio de sua composição interprofissional, que inclui médico generalista, enfermeiro, técnicos de enfermagem, agentes comunitários de saúde e equipe de saúde bucal - dentistas e auxiliares de saúde bucal (Brasil, 2006). Além disso, desde 2008, a AB conta com o Núcleo de Apoio à Saúde da Família (NASF), que tem por objetivo ampliar a abrangência das ações das equipes ESF, aumentando a resolutividade da $\mathrm{AB}$ e promovendo um cuidado integral a partir da incorporação de profissionais de diferentes áreas, incluindo o psicólogo (Brasil, 2014).

Independente da presença do psicólogo neste nível de atenção por meio do NASF ou não, alguns autores (Dimenstein, 1998; Iglesias \& Avellar, 2016; Alexandre \& Romagnoli, 2017; Cintra \& Bernardo, 2017; Tavares Gonçalves \& Diógenes, 2020) apontam que a inserção e efetivação do psicólogo no contexto da AB, têm encontrado dificuldades, visto que muitos profissionais buscam transpor para o setor público de saúde o modelo tradicional clínico, pautado em questões individuais e com foco no transtorno psíquico. Um dos fatores destacados para a ocorrência desse problema se refere ao processo de formação desses profissionais, que, por vezes, prioriza uma única forma de atendimento e compreende o indivíduo sem levar em consideração o contexto social no qual se insere (Dimenstein, 1998; Rechtman \& Bock, 2019).

Esse modelo de atendimento clínico, no qual o adoecimento é visto como resultado, restritamente, de fatores individuais, é contrário ao conceito de saúde defendido pelo SUS, que contempla, para além de aspectos individuais, condições sociais e culturais da população atendida (Cintra \& Bernardo, 2017). Neste sentido, umas das prioridades do psicólogo que atua nesse nível de atenção, deve ser o conhecimento sobre o território no qual os usuários do serviço residem, o que ultrapassa o saber que diz respeito somente a técnicas ou ao setting tradicional (Alexandre \& Romagnoli, 2017).

Nesta perspectiva, o profissional psicólogo deve, no seu fazer cotidiano, se inserir na comunidade, facilitando a compreensão das dinâmicas existente no território, bem como seus símbolos e códigos (Cintra \& Bernardo, 2017). Assim pode construir estratégias de intervenções e atividades possíveis e conectadas com a vida e as necessidades dos usuários (Dimenstein, 1998; Conselho Federal de Psicologia, 2019). Espera-se que o psicólogo na AB não atue como um colonizador de corpos e sentidos, mas que produza com sua prática "empoderamento de indivíduos e coletividades, possibilitando que eles promovam mudanças em suas vidas" (Cintra \& Bernardo, 2017, p. 886; Conselho Federal de Psicologia, 2019).

Tais colocações não buscam extinguir a modalidade de atendimento individual no âmbito da $\mathrm{AB}$, já que em algumas situações há a necessidade de atendimento dessa forma, mas concebê-la como mais uma ferramenta e não como a principal ou única. Neste sentido, destacam-se outras maneiras de atuação do psicólogo na $A B$, como visitas domiciliares, oficinas e atividades em grupo, dentre outras (Cintra \& Bernardo, 2017).

As atividades e ações grupais têm ocupado um lugar central nas portarias e programas de saúde pública no Brasil, sobretudo aquelas referentes à $\mathrm{AB}$. No entanto, na prática, ainda sobressaem as intervenções individuais em detrimento das coletivas. Tal fato está relacionado também, a carência de disciplinas que abordem a temática de grupos na matriz curricular dos cursos, que formam profissionais para atuarem na saúde (Furlan \& Campos, 2010).

Em relação a Psicologia, por exemplo, uma pesquisa feita com 18 psicólogos sobre a execução de atividades grupais demonstrou que os profissionais tinham dúvidas, receios e despreparo para conduzir tal prática (Rasera \& Rocha, 2010). Outro estudo feito com 346 psicólogos do Brasil sobre práticas desempenhadas no contexto da saúde pública, demonstrou que apenas 10,4\% realizavam atendimento grupal, contra 42,1\% que atuavam com base no modelo clínico tradicional (Spink et al., 2006). 
Apesar dessas dificuldades e da fragilidade que tem configurado as práticas grupais, há muitos aspectos positivos em sua realização no contexto da AB (Sangioni et al.. 2020). O grupo se afirma como uma ferramenta que favorece a comunicação entre profissionais e usuários e, também, permite que outras questões, para além do adoecimento, possam ser compartilhadas e discutidas. Além disso, no grupo as pessoas se expressam não só por meios verbais, mas por simbólicos e mensagens corporais. Neste sentido, cabe ainda ressaltar que no ambiente grupal na AB, os usuários podem se sentir mais confortáveis para se expressar e para compartilhar experiências, até porque esse ambiente, normalmente, é composto por pessoas que moram no mesmo território, ou seja, compartilham de pensamentos, hábitos, valores e situações parecidas (Furlan \& Campos, 2010).

Neste sentido, as semelhanças presentes na vida dos integrantes do grupo, juntamente com a troca de experiência, permite que seja construído vínculos entre os usuários, que extrapolam os espaços físicos da instituição de saúde e se façam presentes no cotidiano dos mesmos. A partir dessa premissa, é possível pontuar que no grupo há a possibilidade do saber não ficar restrito à figura do profissional de saúde. Para tanto, é necessário que as atividades desenvolvidas no contexto grupal sejam baseadas em relações transversais, não só pelo fato de todos serem dotados de saber, mas porque o profissional também está exposto a compartilhar suas experiências (Furlan \& Campos, 2010).

Diante disso, é possível pontuar que o grupo, assim como o acolhimento, é um mecanismo que pode alcançar resultados condizentes com os fundamentos da $\mathrm{AB}$, a produção de vínculo entre a equipe e a população que, por sua vez, resultam na continuidade do cuidado (Brasil, 2006). No entanto, nem sempre esses dispositivos alcançam isso, visto que muitos grupos são feitos apenas em resposta a grande demanda (Rasera \& Rocha, 2010), outros ainda sequer chegam a se configurar como grupo, e sim um agrupamento, ou seja, várias pessoas reunidas com queixas diversas, mas sem conexão, sem levar em consideração o que essas queixas têm em comum (Furlan \& Campos, 2010). E têm aqueles grupos que adquirem formato de palestra, cujo objetivo é apenas transmissão de informações do profissional para o usuário (Brasil, 2013b).

Os grupos na $\mathrm{AB}$, normalmente, se enquadram no último caso, já que se orientam por ações que focalizam agravos ou doenças específicas, como diabetes, hipertensão e outros. Contudo, há outras possibilidades de atividades grupais nesse contexto, como aqueles que se organizam no campo da saúde mental: grupos terapêuticos, grupos operativos, grupos de convivência, grupos de artesanato ou de geração de renda (Brasil, 2013b).

Nesta direção, cabe ressaltar que a inserção de atividades e intervenções a respeito da saúde mental na AB, contribui para reduzir o estigma atrelado ao sofrimento psíquico, além de expandir o acesso dos usuários nesse âmbito, uma vez que a $\mathrm{AB}$ é a porta de entrada preferencial do usuário nos serviços de saúde e o nível de atenção mais próximo do dia a dia da comunidade, se tornando um ponto estratégico na orientação de práticas de cuidado (Machado e Pereira, 2013; Machado e Gomes, 2018).

Assim, considerando a potencialidade do acolhimento e das intervenções grupais no contexto da $A B$, esse trabalho busca apresentar as possibilidades e os desafios da junção desses dois dispositivos, a partir de um relato de experiência de acolhimento grupal em saúde mental em uma Unidade de Saúde da Família (USF).

\section{Metodologia}

Este trabalho se apresenta como um estudo descritivo qualitativo, do tipo relato de experiência. Esse tipo de trabalho tem como característica a descrição de contextos, vivências e experiências que proporcionam reflexões e/ou novas perspectivas sobre determinado fenômeno (Lopes, 2012). Dessa forma, esse manuscrito foi construído a partir da inserção no cotidiano de uma USF por meio do Projeto de Extensão "Promoção à Saúde na Atenção Básica". Esse 
Projeto de Extensão está vinculado à Universidade Federal do Espírito Santo, mais precisamente aos Departamentos de Psicologia e Terapia Ocupacional, e tem como objetivo implementar e/ou ampliar as práticas e ações coletivas de promoção à saúde na Atenção Básica, junto às equipes de saúde, de acordo com as necessidades de cada território.

O projeto de extensão "Promoção à Saúde na Atenção Básica" é composto por estudantes da Psicologia, da Terapia Ocupacional e por professoras das duas áreas, além de profissionais da Atenção Básica, de modo que a atuação e a realização das atividades ocorrem em três das 29 Unidades de Saúde do município. Para tanto, são realizadas idas a campo pelas extensionistas e supervisão, ambas de caráter semanal. A respeito das supervisões cabe destacar a importância desses espaços, não só no que diz respeito a discussão teórica, mas pela possibilidade de compartilhar as angústias, descobertas e experiências vividas, bem como pensar e construir conjuntamente estratégias para estar e atuar na Atenção Básica. A prova disso é que a estratégia de acolhimento grupal a ser apresentada neste estudo, foi pensada e elaborada em supervisão, incluindo, na ocasião, a psicóloga da USF em questão.

A USF na qual se passa essa experiência é referência para os moradores de quatro bairros da periferia do município de Vitória/ES, totalizando 11.855 habitantes (Instituto Brasileiro de Geografia e Estatística, 2010). O território abriga um quantitativo importante de pessoas em situação de vulnerabilidade, decorrente da baixa renda familiar, violência e tráfico de drogas. Apesar dessa condição, essa população tem acesso a escolas, creches, Centro de Referência da Assistência Social (CRAS), USF, além da assistência da Legião da Boa Vontade - instituição beneficente e filantrópica.

Essa Unidade abrange quatro equipes de Saúde da Família (eSF) e apesar de não ser composta oficialmente de equipe NASF, possui, para além daqueles tidos como profissionais básicos para o funcionamento da ESF, os seguintes profissionais de apoio: assistente social, farmacêutico, profissional de educação física e psicólogo. Essa particularidade na configuração da equipe de saúde da Unidade se justifica pelo fato do município de Vitória ter inserido diferentes profissionais na Atenção Básica no ano de 2007 - antes mesmo da publicação da portaria 154/2008 que implanta os NASF no país - com o intuito de ampliar a capacidade de resolutividade no território, bem como responder às necessidades de cuidado da população e fortalecer programas da Atenção Básica, tais como Programa de Saúde Mental, Programa Saúde na Escola e Programa de Saúde da Mulher (Calente, 2017; Belotti, 2019).

Neste contexto, a Psicologia compõe essa USF a algum tempo e atualmente oferta as seguintes atividades: atendimento individual, acolhimento grupal em saúde mental, grupo de mulheres, grupo de saúde mental e grupo de adolescentes. Algumas dessas atividades acontecem em conjunto com outros profissionais, tais como o grupo de saúde mental e grupo de adolescentes, que ocorrem a partir da parceria com o Serviço Social. Além disso, a Psicologia está presente em outros espaços que compõem a dinâmica da USF, como matriciamento, colegiado gestor, discussão de casos com a equipe, atendimento compartilhado, visita domiciliar e outros.

Vale destacar a diferença entre o "acolhimento grupal em saúde mental" e o "grupo de saúde mental". O primeiro, normalmente, é destinado às pessoas que buscam a Unidade para um primeiro contato com o serviço de Psicologia, enquanto o segundo têm um caráter longitudinal, visto que as pessoas participantes desse grupo se encontram toda semana e, assim, possuem um vínculo maior.

Destaca-se neste estudo o "acolhimento grupal em saúde mental", que nem sempre teve essa configuração; pois antes dessa intervenção, $\mathrm{o}$ acolhimento tinha um caráter individual, de maneira que as pessoas marcavam a consulta e, a partir da escuta, a psicóloga pensava estratégias que poderiam ser mais eficazes para cada queixa. Contudo, a psicóloga apresentava-se insatisfeita com o modelo individual, devido à baixa oferta de vagas frente à grande demanda da população e à impossibilidade de provocar relações e assim afirmar a potencialidade dos espaços coletivos na atenção à saúde. 
Após discussão foi pactuada uma nova organização para o acolhimento, na qual esses momentos passariam de individual para grupal. Dessa forma, esse acolhimento grupal passou a funcionar às segundas-feiras, de 09:00 às 11:00, conduzido pela psicóloga da Unidade e uma graduanda em Psicologia, extensionista no projeto "Promoção à Saúde na Atenção Básica". Esse acolhimento foi divulgado dentro da Unidade nas reuniões de equipe e por meio de conversas informais com aqueles profissionais que não participam de reunião de equipe. Em cada encontro de acolhimento grupal participavam cerca de cinco usuários, pessoas que buscam o primeiro atendimento psicológico ou que são encaminhadas por outros profissionais da USF. O número pequeno de participantes se deve à precária infraestrutura da USF, de modo que é necessário que este grupo aconteça dentro de um consultório de atendimento individual. Além disso, o acolhimento acontece restritamente em um dia da semana, pois é um dos três turnos em que a psicóloga tem uma sala de consultório destinada para suas atividades. A equipe entendeu que não seria interessante esse acolhimento acontecer em espaço físico fora da USF, para garantir que fosse um lugar possível para todos, considerando diferenças religiosas, rivalidades do tráfico etc. Esse formato de acolhimento aconteceu durante seis meses, sendo interrompido em março de 2020 em razão da pandemia de COVID-19, mas com perspectivas de retorno, assim que a secretaria de saúde liberar o retorno de grupos.

Um recurso utilizado para registrar esses encontros foi o diário de campo, que permite registrar os fatos ocorridos e os sentimentos vividos durante a experiência, além de facilitar o processo de reflexão sobre as condutas e estratégias adotadas no grupo (Freitas e Pereira, 2018). Neste sentido, o diário de campo adquiriu o papel de uma ferramenta que auxiliava nas supervisões e no processo formativo, já que possibilitou repensar a atuação e confeccionar esse relato de experiência.

No processo de elaboração deste trabalho foram seguidos os procedimentos éticos, garantindo sigilo, confidencialidade e proteção da identidade dos participantes. Dessa forma, não se utilizou das informações em prejuízo das pessoas e/ou da comunidade.

\section{Resultados e Discussão}

No início do acolhimento era realizado uma breve apresentação das condutoras e uma fala no sentido de acolher os usuários, com vistas a reconhecer as possíveis dificuldades na busca de ajuda no âmbito da saúde mental, pois a sociedade ainda associa a pessoa que frequenta, ou que já frequentou, algum tipo de serviço de saúde mental ao estigma da loucura (Sousa et al., 2018; Nascimento \& Leão, 2019). Desse modo, esses usuários, muitas vezes, são vistos como inferiores, incapazes e desacreditados socialmente. Além disso, ao internalizar tal estigma, essas pessoas podem ter repercussões negativas em sua autoestima, senso de eficácia e em suas relações interpessoais (Nascimento \& Leão, 2019).

Posteriormente era feito o "pacto de confiança", cuja finalidade era sensibilizar os participantes de que naquele espaço todos seriam convidados a falar de si, da sua queixa, da sua vida e que, muitas vezes, ao compartilhar suas questões as pessoas poderiam se sentir vulneráveis. Assim, esse espaço requeria uma postura empática, sem críticas ou exposições de relatos que pudessem constranger ou comprometer alguém em outro espaço, se tratando, portanto, de um ambiente "protegido" e sigiloso. Foi feito então, um contrato com os participantes a respeito da presença nesse espaço, indicando que as anotações feitas por uma das condutoras seria para contribuir no acordo sobre as melhores indicações para cada caso.

Nesta perspectiva, a proposta era afirmar esse acolhimento grupal como uma ferramenta que possibilita a criação de vínculo, capaz de proporcionar um ambiente de escuta qualificada, no qual o usuário consiga expressar suas 
angústias e dificuldades, livre de julgamentos e pré concepções, reconhecendo que a queixa do outro é legítima e singular (Brasil, 2013a; Brasil, 2013b). Dessa forma, acredita-se tornar possível uma escuta sem ruído, sem interferências, de modo que o usuário possa ser ouvido e respeitado em sua singularidade.

A partir desses acordos dava-se início a uma dinâmica que consistia no seguinte: colocava-se sobre a maca do consultório figuras variadas, recortadas aleatoriamente de revistas, jornais e outros materiais impressos (Figura 1), e em seguida, solicitava-se que os usuários escolhessem a imagem que consideravam representar o motivo de sua busca ao atendimento psicológico ou que pudesse representar algo do seu percurso de vida. Com base em tal escolha, cada usuário era convidado a se apresentar para o grupo e dizer o motivo de escolher aquela figura.

Figura 1: Imagens utilizadas durante o acolhimento grupal.

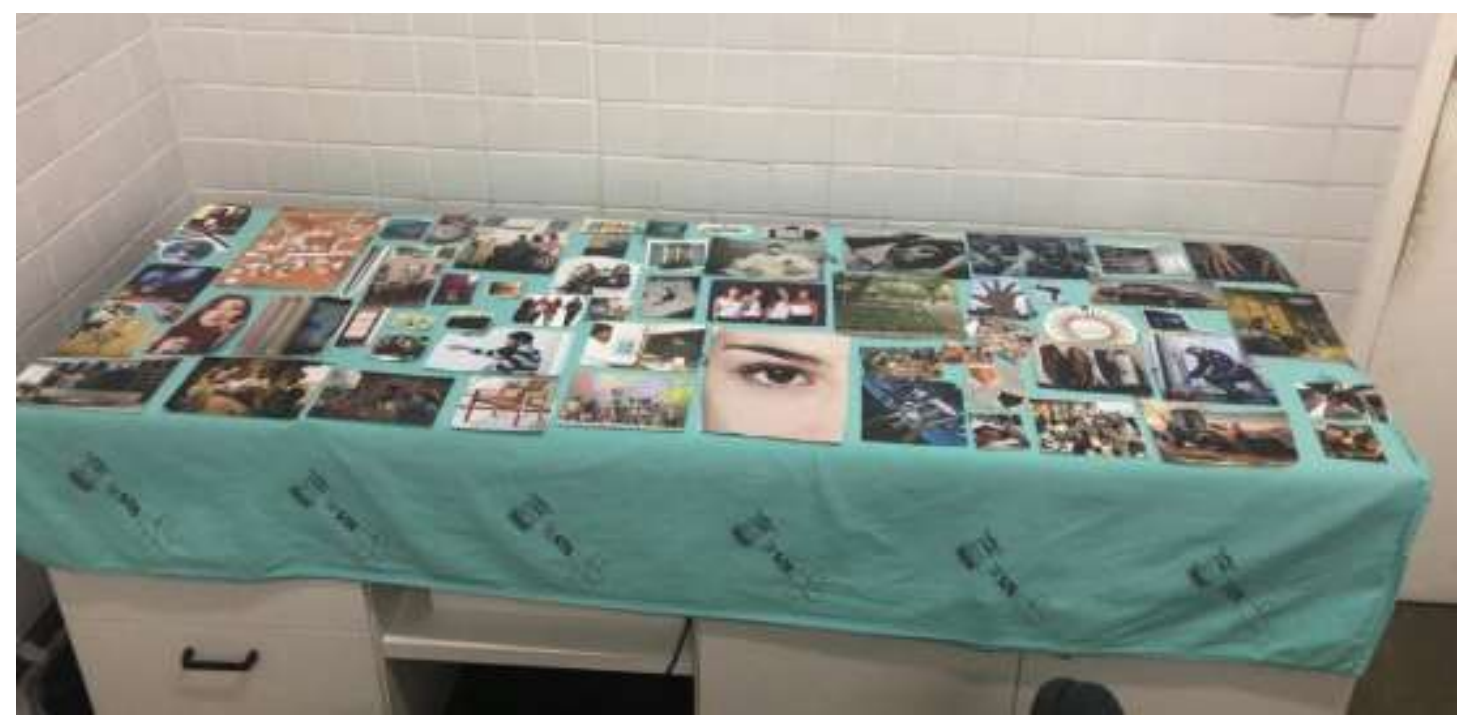

Fonte: Autores.

A escolha por tal dinâmica de apresentação de imagens, se deu pelo fato de que "atividades expressivas e dinâmicas podem potencializar que o difícil de ser dito seja trazido à tona, (...), podem implicar também em aumento de adesão e participação" (Furlan \& Campos, 2010, p. 108). Além disso, o recurso da imagem "nos faz pensar, evoca uma história, metaforiza uma outra situação, traz-nos, por analogia, uma lembrança ou, às vezes, somente uma ambiência afetiva" (Vacheret, 2008, p. 186). Desta forma, utilizar dessa dinâmica poderia facilitar os usuários no momento de falar de si, de sua vida e de sua queixa.

De início alguns usuários ficavam tímidos e quietos, outros conseguiam se expressar mais facilmente, porque já conheciam a psicóloga de outros momentos ou porque conseguiam associar rapidamente sua queixa à imagem. Haviam outros que questionavam a obrigatoriedade de falar na presença de todo grupo, porque estavam com vergonha ou ainda porque achavam "seu problema" muito constrangedor. Diante disso, era pontuado que ninguém era obrigado a compartilhar e que poderiam fazer isso individualmente após o grupo, mas era importante que todos se ouvissem, pois todos ali poderiam ajudar na queixa de alguém ou poderia estar passando por situação parecida à realidade de outra pessoa.

Para Franco e Merhy (2005), a busca pelo serviço de saúde se dá a partir da percepção que o usuário tem do que é ofertado pelo serviço, o qual majoritariamente apresenta práticas que exprimem uma concepção de cuidado como oferta de procedimentos individualizantes. Assim é importante destacar que a maior parte dos usuários que inicialmente 
se colocava desconfortável quanto a esse modelo de acolhimento grupal, a partir da interseção com as demais histórias apresentadas e do manejo das profissionais envolvidas, se abria para novas possibilidades terapêuticas e participava da atividade, inclusive trazendo suas questões. Para os autores (Franco \& Merhy, 2005) é a partir da afirmação desses espaços coletivos de promoção à saúde, mais centrados nos usuários e respeitando sua singularidade, que será possível romper com o imaginário vigente, do atendimento individual como único efetivo no cuidado.

Neste sentido, quando se oferta algo que difere do habitual, os usuários podem ter dificuldades de perceber aquilo como uma ferramenta que busca sua saúde, no sentido amplo. No entanto, é esse o desafio que se apresenta para os profissionais de saúde, o de construir processos de cuidado baseados nas relações, que podem se consolidar como referência para os usuários, e assim lhe ofertar a segurança e potência do cuidado que ele necessita (Franco \& Merhy, 2005)

Desta forma, as condutoras buscavam incentivar a participação dos usuários, pedindo para que relatassem o motivo de escolherem uma imagem, ou contando se já haviam passado por situação parecida e/ou o que fizeram para lidar com aquilo, bem como expressando opiniões ou dúvidas. Neste sentido, a condução do acolhimento grupal por uma dupla facilitava o manejo do grupo, visto que enquanto uma condutora anotava algumas informações importantes relatadas por algum usuário, a outra conseguia se ater mais aos participantes, incluindo a atenção aos seus comportamentos não verbais, por exemplo. Em algumas situações, enquanto algum usuário falava de si, um outro expressava por meio da sua postura corporal ou por expressões faciais, que também estava passando por aquilo ou já havia passado. Ao perceber essas expressões, as condutoras estimulavam os usuários a se expressarem: "vi que você começou a balançar a cabeça em sinal afirmativo quando ele falou, você tem passado por isso também? Gostaria de falar?"

O manejo do grupo por mais de uma pessoa favorece a melhor apreensão dos movimentos e dos acontecimentos que ocorrem ali, justamente porque uma pessoa sozinha capta menos informações do que duas. Além disso, conduzir junto de outra pessoa possibilita uma troca, na qual um aprende com o outro como manejar o grupo (Furlan \& Campos, 2010). No entanto, cabe ressaltar que o manejo de grupo por duplas requer que os profissionais envolvidos nesse processo estejam alinhados em relação ao propósito do grupo e também na maneira de conceber o usuário como protagonista, pois caso contrário pode se tornar mais difícil o manejo dos acontecimentos, bem como a expressão dos usuários.

Assim, aos poucos os usuários iam se aproximando afetivamente uns dos outros em suas histórias, se sentindo mais à vontade para compartilhar e intervir um na fala do outro, o que foi entendido como uma construção de confiança com aquele que vivencia, por vezes, experiências comuns naquele território. Em um desses acolhimentos grupais, uma mãe relatou seus problemas com o filho, que apresentava, naquele momento, comportamentos para chamar sua atenção, como, por exemplo, entrar na frente do celular enquanto ela mexia e chamá-la para brincar todo tempo. Essa mãe falou ainda de sua rotina corrida e que não tinha tempo para ficar com o filho, então tentava compensá-lo dando presentes. Após o relato dessa mãe, as condutoras perguntaram se alguém ali passava pela mesma situação ou se alguém já havia passado por algo semelhante para contar como conseguiu lidar com aquilo.

Ao ouvirem isso e relatarem outras experiências parecidas, surgiram propostas no sentido das pessoas ligadas às crianças poderem fazer mais atividades juntas, já que, aparentemente, a questão apresentada se relacionava a falta da presença da mãe, no caso específico relatado. Surgiram ideias no sentido da mãe tentar ler para o filho antes de dormir e estabelecer um dia na semana, no qual pudessem assistir a um filme juntos, por exemplo. Para além disso, o tom da discussão veio no sentido desta mãe não se culpar por essa realidade, vivenciada também por outras pessoas e "resolvida" dentro das possibilidades de cada um. Nesta direção, cabe ressaltar a receptividade dessa mãe às falas dos 
outros participantes do grupo, evidenciando que aquilo que foi dito fez sentido para ela, a partir da realidade dela e do filho.

Entende-se que tal ocorrido indica a potencialidade do dispositivo grupal, que "permite uma poderosa e rica troca de experiências e transformações subjetivas que poderia não ser alcançável em um atendimento de tipo individualizado" (Brasil, 2013b, p. 121). Além disso, ao estimular a participação dos usuários, busca-se fortalecer seu processo de reflexão, evidenciando que ele é capaz de propor estratégias, tomar decisões, contribuir com o outro, agir coletivamente (Zara et al., 2008).

Em outro acolhimento grupal, um adolescente que alegou estar com sintomas depressivos compartilhou como estava sendo difícil passar por aquela fase, na qual não tinha ânimo para fazer nada, só queria ficar deitado dentro do quarto e ninguém da sua família conseguia entendê-lo. Ao ouvir isso, uma participante do grupo disse entender perfeitamente o que ele estava vivenciando, pois ela também passava por aquilo e constantemente ouvia do marido que ela não fazia suas atividades porque não queria ou porque era preguiçosa.

De acordo com Nascimento e Leão (2019), às vezes, os familiares entendem o transtorno mental como algo que pode ser controlado pela pessoa acometida. A partir de tal compreensão, a pessoa está sofrendo por sua escolha e só depende dela sair dessa situação. Além disso, as autoras enfatizam que tal compreensão faz com que os usuários se sintam incompreendidos e solitários. Contudo, no grupo, os usuários podem falar de sua dor sem serem julgados, nesse movimento se reconheceram em seus sofrimentos e se sentiram compreendidos, uma vez que o grupo possibilita sentimentos de reciprocidade e solidariedade (Zara et al., 2008; Furlan \& Campos, 2010).

Para Merhy (2014), o processo de produção de atos cuidadores em saúde é sempre relacional, ou seja, é a partir do encontro e do que é constituído nessa interseção que torna se possível desenhar novos processos para os sujeitos. É essa interseção que permite a construção de fluxos e conexões que se colocam no plano de produção do cuidado (Franco $\&$ Merhy, 2013). Assim, destaca-se o potente caráter terapêutico que o próprio encontro do acolhimento nos apresenta neste movimento de trocas e escutas, pautadas a partir das relações geradas.

Após o relato dos participantes há um intervalo de 10 a 15 minutos, em que os usuários saem da sala para beber água, por exemplo, e as condutoras aproveitam para iniciar a discussão dos casos e pensar possibilidades de continuidade do cuidado para cada participante. Vale destacar que este momento foi pensado estrategicamente para que as condutoras pudessem trocar algumas impressões e, conjuntamente, levantar propostas para compartilhar com os usuários. Após o intervalo, os usuários retornam para a sala e, antes de apresentar as propostas de cuidado pensadas, as condutoras fazem uma fala com o propósito de apresentar quais são as possibilidades de atuação da Psicologia dentro da AB.

Com isso, busca-se desconstruir o entendimento de que a Psicologia se restringe ao atendimento individual, uma crença que ainda está enraizada na concepção dos usuários, de membros da equipe e até de alguns profissionais da área (Alexandre \& Romagnoli, 2017; Cintra \& Bernardo, 2017). Neste sentido, são apresentadas as atividades grupais desenvolvidas pela Psicologia na USF, bem como os serviços que estão no território ou que podem ser acionados e juntos formam uma rede de dispositivos, que atuam na promoção à saúde e garantia do direito, tais como: o CRAS, o Centro de Atenção Psicossocial (CAPS), o Centro de Referência de Atendimento ao Idoso (CRAI), o Centro de Referência de Atendimento à Mulher em Situação de Violência (CRAMSV), o Serviço de Atendimento à pessoa em situação de Violência (SASVV) e o Centro Esportivo Tancredo de Almeida Neves.

Posteriormente, são apresentadas as propostas pensadas inicialmente, para os usuários e solicitado que eles expressem se aquela indicação faz sentido naquele tempo e espaço, visto que uma postura acolhedora pressupõe o protagonismo do usuário, "de modo que a resposta dada ao problema seja com ele pactuada, conjugando suas necessidades imediatas com o cardápio ofertado pelos serviços" (Hoffman, 2009, p. 42). Em alguns casos, o próprio 
momento de acolhimento é suficiente para atender a queixa inicial do usuário, mas a maior parte dos casos é absorvido em alguma atividade da própria USF, sobretudo as atividades de grupo, isso porque as condutoras apostam "que o grupo potencializa (...) identificações que ajudam aos seus integrantes na busca de ações emancipatórias e de auto-cuidado.” (Zara et al., 2008, p. 83). Cabe destacar que a experiência do usuário no acolhimento em grupo reduz a resistência dos encaminhamentos aos espaços coletivos.

Em outros casos, o usuário é indicado a outro serviço, por conta das especificidades da queixa, ou a outro profissional dentro da própria USF. Essas indicações são feitas de forma corresponsável, de modo a orientar o usuário e sua família para que esse cuidado possa ter continuidade. Entende-se que essa conduta também faz parte de uma postura acolhedora da $\mathrm{AB}$, uma vez que mesmo o usuário seguindo para o cuidado em outro serviço, a $\mathrm{AB}$ continua ali como um espaço de investimento na promoção à saúde do território o qual ele faz parte (Iglesias et al, 2009; Brasil, 2010).

Ao final de cada acolhimento grupal é solicitado aos usuários dizerem como foi participar daquele momento em grupo, quais foram os aspectos positivos e negativos. A maioria afirma ser um momento muito positivo, que estranharam no início todas as pessoas entrando na mesma sala, mas que depois foi uma experiência muito mais leve e tranquila do que imaginaram e não sabiam que o atendimento psicológico poderia adotar aquele formato. Além disso, há muitos relatos dizendo que o fato de estar com outras pessoas tornou mais fácil o processo de falar de si, seja porque aconteceu uma identificação ao ouvir outra pessoa, ou pelo fato de se sentirem ouvidos e acolhidos por tantas pessoas.

Tendo em vista essa experiência de acolhimento grupal, é importante ressaltar que não há um modelo ideal de funcionamento de grupo, sendo necessário, portanto, se atentar para as especificidades que cada contexto apresenta. Durante a realização desses acolhimentos grupais foi necessário alterar alguns caminhos que tinham sido traçados previamente, visto que esses atrapalhavam a possibilidade de troca do grupo, resultando em um agrupamento de pessoas.

Uma dessas mudanças foi a separação do acolhimento grupal por faixa etária, de modo que os adultos, as crianças e os adolescentes tinham dias específicos para serem acolhidos. Tal mudança se fez necessária quando as condutoras sentiram que os adolescentes falavam pouco ou quase nada, quando estavam rodeados de adultos, que às vezes relatavam problemas com os filhos. Nestas condições, os adolescentes pediam para falar ao final do grupo, porque sentiam que ali ninguém iria entendê-los.

Outra modificação foi o atendimento dos adolescentes sem a presença dos pais na sala. Orientava-se os pais a esperar próximo a sala e eles só entravam no momento da devolutiva dos filhos. Tal medida foi adotada a partir da observação de que, na presença dos pais, muitos adolescentes não falavam por si, deixavam que os pais o fizessem, embora algumas vezes demonstrassem que não concordavam com o que estava sendo dito. No que diz respeito ao atendimento das crianças, optou-se por fazer o primeiro atendimento só com os pais e depois com os dois juntos, ou só com a criança. Algumas crianças se sentiam extremamente constrangidas ao ouvirem os pais falarem delas para outros pais e na presença de outras crianças. Tais modificações possibilitaram um melhor aproveitamento do grupo, visto que ao dividir por faixas etárias, os usuários conseguiam se identificar com a queixa um dos outros, resultando em uma troca mais potente.

Um exemplo de como essa mudança possibilitou trocas mais ricas, consiste em um encontro com cinco adolescentes, no qual um deles se mostrava bastante resistente em ir à USF. Alegou que estava ali porque a mãe a obrigou, por entender que a adolescente estava tendo que lidar com muitos problemas familiares. No início do acolhimento a adolescente se mostrava bastante ríspida, recusando-se a escolher uma imagem que representasse algo de sua vida. As condutoras e os demais integrantes do grupo respeitaram a sua vontade e conforme os outros adolescentes falavam de si e do motivo de estarem ali, a adolescente foi se soltando e trocando informações no grupo. 
Ao final do encontro a adolescente fez o seguinte relato: "cada um de nós tem um problema, né? Tem uns que são parecidos, outros nem tanto, mas todo mundo tem". E finalizou perguntando se aqueles encontros aconteciam mais vezes, pois foi melhor do que ela imaginava.

Além de todas as potencialidades já mencionadas dessa experiência, esse formato de acolhimento também proporcionou conhecer ainda melhor a realidade da população adscrita à USF e, assim, construir ações e atividades que fazem sentido para aquela comunidade. Observou-se, por exemplo, a necessidade de desenvolver alguma atividade voltada para pais e mães, devido ao elevado número de pais que buscavam o serviço relatando problemas com os filhos.

Contudo, é necessário pontuar também, que os encontros trazem o elemento do inesperado na raiz de sua constituição. Esse ineditismo exige uma postura atenta das condutoras, frente aos desafios que se colocam para serem manejados, como, por exemplo: monopolização da fala por parte de algum participante, dificuldade do participante se expressar em grupo, constituir grupalidade de forma breve, despertar uma postura empática em todos os participantes, dentre outros. Com o objetivo de administrar essas questões e os efeitos que as mesmas causavam nas condutoras, destaca-se a importância do trabalho ser realizado em dupla e a existência de supervisões, onde foi possível compreender e dar sentido também a esses movimentos.

\section{Considerações Finais}

A efetivação do acolhimento proposto pela PNH no cotidiano da AB requer uma mudança de postura dos profissionais de saúde. Isso só é possível a partir de um exercício diário, no qual há a escuta de alguém que sofre e o reconhecimento desse alguém como detentor de uma história e um saber. Colocar isso em prática, no entanto, caminha a curtos passos, visto que adotar uma postura acolhedora exige abandonar caminhos e ações atualmente dominantes, como o automatismo de se relacionar com as pessoas, a concepção de saber o que é melhor para o outro, por conta do grau de escolaridade, e a atuação descolada do contexto de quem sofre.

Nesta perspectiva, a Psicologia ainda tem tido dificuldades em uma prática efetiva no contexto da AB. Contudo, tem-se buscado um exercício da profissão condizente com a proposta do SUS, que aposta na autonomia do sujeito, bem como no fortalecimento do território, já que saúde não pode ser dissociada de aspectos sociais. Nesta direção, a utilização do recurso de grupos comparece como dispositivo potente, que possibilita a troca entre diferentes sujeitos, o conhecimento da realidade do território e a tomada de decisão pactuada entre profissionais e usuários.

Apesar da potencialidade existente nessa experiência de acolhimento em grupo, é preciso sinalizar limitações do contexto desta USF. O fato desse acolhimento acontecer apenas um dia na semana, faz com que tenha um intervalo muito grande entre o acolhimento da mesma faixa etária no mês, por exemplo. Tal configuração decorrente da precária infraestrutura da USF, demonstra que a falta de espaços adequados pode ser um obstáculo para o psicólogo na realização de outras atividades de atendimento clínico.

Ademais, o grupo poderia ser realizado juntamente a outros profissionais da USF, já que o acolhimento é um dispositivo a ser exercido por todos os profissionais e a saúde mental não se restringe ao saber do psicólogo. No entanto, na prática a saúde mental ainda é vista como algo distante do campo central de saber e de intervenção das demais categorias da saúde, não despertando o interesse da equipe para tais atividades, além da dificuldade em conciliar o escasso espaço físico e as agendas profissionais, o que pode sinalizar importantes aspectos a serem discutidos em espaços de Educação Permanente. Embora essa articulação tenha se mostrado difícil dentro da equipe, a parceria com a Universidade, por meio do projeto de extensão, tem se mostrado como uma importante via para reflexão e discussão deste dispositivo. 
O acolhimento em grupo dentro dessa USF, portanto, tem se apresentado como uma importante ferramenta de compartilhamento, de escuta e de criação de vínculos. Essa experiência demonstrou que um acolhimento potente é aquele que se dá em todas as direções possíveis: usuário-usuário, profissional-usuário, usuário-profissional. Neste sentido, todos os envolvidos se acolhem nesses encontros, assim, eu acolho, tu acolhes, nós acolhemos.

Para trabalhos futuros, sugere-se a incorporação de profissionais de diferentes áreas no acolhimento, tendo em vista que saúde mental não se restringe à psicologia. Além disso, sugere-se que esse serviço ocorra com maior frequência, não uma vez na semana, e a implantação de alguma ferramenta de avaliação feita pelos usuários, com intuito de fornecer informações para análise posterior dos efeitos de tais intervenções de cuidado na saúde da população atendida, bem como constatar possíveis melhorias.

\section{Referências}

Alexandre, M. L. \& Romagnoli, R. C. (2017). Prática do Psicólogo na Atenção Básica - SUS: conexões com a clínica no território. Revista Contextos Clínicos, 10(2), 284-299. 10.4013/ctc.2017.102.12

Belotti, M. (2019). Núcleo Ampliado de Saúde da Família: potencialidades, desafios e impasses para um paradigma emergente em saúde. (Tese de Doutorado). Programa de Pós-Graduação em Psicologia, Universidade Federal do Espírito Santo, Vitória, ES. http://repositorio.ufes.br/handle/10/11035

Brasil. (2006). Política nacional de atenção básica (Série Pactos pela Saúde, volume 4) Ministério da Saúde. http://bvsms.saude.gov.br/bvs/publicacoes/politica_nacional_atencao_basica_2006.pdf

Brasil. (2010). Acolhimento nas práticas de produção de saúde. (2a ed.) (Série B. Textos Básicos de Saúde), Ministério da Saúde. http://bvsms.saude.gov.br/bvs/publicacoes/acolhimento_praticas_producao_saude.pdf

Brasil. (2013a). Política Nacional de Humanização $\quad$ (Folheto), Ministério da https://bvsms.saude.gov.br/bvs/publicacoes/politica_nacional_humanizacao_pnh_folheto.pdf

Brasil. (2013b). Saúde Mental. 1ªed. (Cadernos de Atenção Básica, n. 34). Ministério da Saúde. https://aps.saude.gov.br/biblioteca/visualizar/MTIxMQ==

Brasil. (2014). Núcleo de Apoio à Saúde da Família. (Cadernos de Atenção Básica, n. 39). Ministério da Saúde. http://bvsms.saude.gov.br/bvs/publicacoes/nucleo_apoio_saude_familia_cab39.pdf

Calente, D. S. (2017). A experiência do grupo condutor na implantação do NASF em Vitória-ES (Dissertação de Mestrado). Programa de Pós-Graduação em Psicologia Institucional, Universidade Federal do Espírito Santo, Vitória, ES, Brasil. http://repositorio.ufes.br/handle/10/9019

Cintra, M. S., \& Bernardo, M. H. (2017). Atuação do Psicólogo na Atenção Básica do SUS e a Psicologia Social. Psicologia: Ciência e Profissão, 37(4), 883896. https://doi.org/10.1590/1982-3703000832017

Conselho Federal de Psicologia (2019). Referências técnicas para atuação de psicólogas(os) na atenção básica à saúde. Conselho Federal de Psicologia, Conselhos Regionais de Psicologia e Centro de Referência Técnica em Psicologia e Políticas Públicas. (2a ed.), CFP. https://site.cfp.org.br/wpcontent/uploads/2019/11/CFP_atencaoBasica-2.pdf

Dimenstein, M. D. B. (1998). O psicólogo nas Unidades Básicas de Saúde: desafios para a formação e atuação profissionais. Estudos de Psicologia (Natal), 3(1), 53-81. https://dx.doi.org/10.1590/S1413-294X1998000100004

Franco T. B. \& Merhy E. E. (2005). Produção Imaginária da Demanda. In: Pinheiro R., e Mattos R. A, (Org). Construção social da demanda: direito à saúde, trabalho em equipe, participação e espaços públicos. (2a ed.), 181-193. IMS/ UERJ.

Franco, T. B. \& Merhy, E. E. (2013). O reconhecimento de uma produção subjetiva do cuidado. In Franco, T. B., e Merhy, E. E. (Org.) Trabalho, produção do cuidado e subjetividade em saúde: textos reunidos. 151-171.: Hucitec.

Freitas, M., \& Pereira, E. R. (2018). O diário de campo e suas possibilidades. Quaderns de Psicologia, 20(3), 235-244. DOI:https://doi.org/10.5565/rev/qpsicologia.1461

Furlan, P. G. \& Campos, G. W. S. (2010). Os grupos na atenção básica à saúde. In: Brasil, Cadernos HumanizaSUS (Atenção Básica - Série B. Textos Básicos de Saúde, Volume 2, Cap. 7, 105-116. Brasília: Ministério da Saúde. http://bvsms.saude.gov.br/bvs/publicacoes/cadernos_humanizasus_atencao_basica.pdf

Hoffmann, C. (2009). Acolhimento na atenção básica: navegações e mergulhos nos discursos e práticas produzidos no cotidiano de uma unidade de saúde da família (Dissertação de Mestrado). Programa de Pós-Graduação em Psicologia Institucional, Universidade Federal do Espírito Santo, Vitória, ES, Brasil. http://repositorio.ufes.br/handle/10/6718

Instituto Brasileiro de Geografia e Estatística. (2010). População no último censo: Censo Demográfico. http://legado.vitoria.es.gov.br/regionais/dados_socioeconomicos/populacao/2000_2010/tab5.asp

Iglesias, A., Guerra, B. C., Soares, J., \& Araujo, M. D. (2009). Análisis de las acciones de promoción de la salud realizadas por psicólogos en Vitória (ES). Psicologia: teoria e prática, 11(1), 110-127. http://pepsic.bvsalud.org/scielo.php?script=sci_arttext\&pid=S1516-36872009000100010\&lng=pt\&tlng=. 
Research, Society and Development, v. 11, n. 1, e34211124977, 2022

(CC BY 4.0) | ISSN 2525-3409 | DOI: http://dx.doi.org/10.33448/rsd-v11i1.24977

Iglesias, A. \& Avellar, L. Z. (2016). As Contribuições dos Psicólogos para o Matriciamento em Saúde Mental. Psicologia: Ciência e Profissão, 36(2), 364-379. https://dx.doi.org/10.1590/1982-3703001372014

Lazzarotto, G. D. R. \& Castro, T. de C. M. (2017). Linhas do acolhimento na saúde: entre modos de trabalhar e acolher. Trabalho (En) Cena, 2(1), 65-79. https://doi.org/10.20873/2526-1487V2N165

Lopes, M. V. O. (2012). Sobre estudos de casos e relatos de experiências. Rev. Rene, 13(4), 1. https://www.redalyc.org/articulo.oa?id=324027983001.

Machado, M. P. \& Pereira, M. A. O. (2013). Percepção da doença mental por profissionais de saúde: possibilidades de ampliação do cuidado. Estud. pesqui. psicol., 13(1), 125-138. http://pepsic.bvsalud.org/scielo.php?script=sci_arttextepid=S1808-42812013000100008elng=ptetlng=pt.

Machado, M. L. M. \& Gomes, A. P. F. (2018). Percepção dos profissionais de saúde quanto ao efeito de um grupo de apoio à saúde mental na atenção primária à saúde. Revista Saúde Pública,1(1), 35-46. https://doi.org/10.32811/2595-4482.2018v1n1.38

Merhy, E. E. (2014). Saúde: a cartografia do trabalho vivo (4a ed.). Hucitec.

Nascimento, L. A. \& Leão, A. (2019). Estigma social e estigma internalizado: a voz das pessoas com transtorno mental e os enfrentamentos necessários. História, Ciências, Saúde-Manguinhos, 26(1), 103-121. https://dx.doi.org/10.1590/s0104-59702019000100007

Rasera, E. F. \& Rocha, R. M. G. (2010). Sentidos sobre a prática grupal no contexto de saúde pública. Psicologia em Estudo, 15 (1), $35-44$. https://doi.org/10.1590/S1413-73722010000100005

Rechtman, R., \& Bock, A. M. B. (2019). Formação do Psicólogo para a Realidade Brasileira: Identificando Recursos para Atuação Profissional. Psicologia: Teoria e Pesquisa, 35, e3551. https://doi.org/10.1590/0102.3772e3551.

Sangioni, L. A., Patias, N. D., \& Pfitscher, M. A. (2020). Psicologia e o Grupo Operativo na Atenção Básica em Saúde. Revista da SPAGESP, 21(2), 23-40. Recuperado de: http://pepsic.bvsalud.org/scielo.php?script=sci_arttext\&pid=S1677-29702020000200003\&lng=pt\&tlng=pt.

Sousa, P. F., Maciel, S. C. \& Medeiros, K. T. (2018). Paradigma biomédico x psicossocial: onde são ancora das as representações sociais acerca do sofrimento psíquico? Temas em Psicologia, 26(2), 883-895. https://dx.doi.org/10.9788/TP2018.2-13Pt

Spink, M. J. P; Bernardes, J. \& Menegon, V. S. M. (2006). A Psicologia em diálogo com o SUS: Prática Profissional e Produção Acadêmica. São Paulo: Associação Brasileira de Ensino de Psicologia e Ministério da Saúde, 1-98. http://www.bvs-psi.org.br/local/file/PsicologiaemDialogoSUS2006.pdf

Tavares Gonçalves, S.; \& Diógenes, J. M. P. (2020). A atuação do psicólogo no Núcleo Ampliado de Saúde da Família e Atenção Básica (NASF - AB). Cadernos ESP - Revista Científica da Escola de Saúde Pública do Ceará, [S. 1.], 14(2), 15-23. //cadernos.esp.ce.gov.br/index.php/cadernos/article/view/432.

Vacheret, C. (2008). A Fotolinguagem(-): um método grupal com perspectiva terapêutica ou formativa. Psicologia: teoria e prática, 10(2), 180-191. http://pepsic.bvsalud.org/scielo.php?script=sci_arttextepid=S1516-36872008000200014elng=ptetlng=pt.

Zara, A. F. P; Trautwein, C. T. G; Aquino, J.C; D’Urso, L. \& Siebert, M. C. (2008). Grupo de Acolhimento em Saúde Mental e Reabilitação na Atenção Básica: uma reflexão sobre a potência de dispositivos grupais. Psic. Rev, 17(1 e 2), 77-97. https://revistas.pucsp.br/psicorevista/article/view/18022 